GU J Sci, Part C, 5(4): 179-185 (2017)

Gazi Üniversitesi
Fen Bilimleri Dergisi
PART C: TASARIM VE TEKNOLOJI
dergipark.gov.tr/http-gujsc-gazi-edu-tr

\title{
Yeni Nesil MIL-101 Malzemesi Sentez ve Karakterizasyon Çalışmaları
}

\author{
Emine KAYA EKINCI ${ }^{1, *}$ \\ ${ }^{1}$ Gazi Üniversitesi, Mühendislik Fakültesi, Kimya Mühendisliği Bölümü, 06570, Maltepe/ANKARA
}

\begin{abstract}
Öz
Makale Bilgisi

Başvuru: 17/04/2017

Düzeltme: 20/11/2017

Kabul: 20/11/2017

Bir tür Metal Organik Çerçeve (MOF) olan MIL-101, son y1llarda kimya endüstrilerinde umut verici uygulamaları ile dikkati çekmektedir. MIL-101 aynı zamanda "Gözenekli Krom Tereftalat" olarak da bilinir. Çok yüksek yüzey alanı ve gözenek hacmi vardır. MIL-101, neme ve diğer kimyasallara karşı olağanüstü dayanıklılık gösterir. Ayrıca kataliz ve adsorpsiyon uygulamaları için elverişli, yüksek konsantrasyonda koordine olarak doymamış $\mathrm{Cr}$ - bölgelerinden oluşur. $\mathrm{Bu}$ çalışmada, MIL-101 hidrotermal yöntemle sentezlenmiş ve X-1şını kırınımı (XRD), azot adsorpsiyon-desorpsiyon analizleri ve taramalı elektron mikroskobu (SEM) ile karakterize edilmiştir. XRD modelleri, yüksek yüzey alanlı $\left(\sim 2400 \mathrm{~m}^{2} / \mathrm{g}\right)$ MIL-101'in kristal yapısının varlığını göstermektedir. Azot adsorpsiyon-desorpsiyon analizleri, malzemenin, mezo-gözenekli malzeme davranışı sergilediğini göstermiştir.
\end{abstract}

\section{Anahtar Kelimeler \\ MIL-101 \\ metal organik çerçeveler gözenekli malzemeler}

Keywords

MIL-101

metal organic frameworks porous materials

\section{Synthesis and Characterization Studies of New Generation}

\section{MIL-101 Materials}

\begin{abstract}
MIL-101, a kind of Metal Organic Frameworks (MOFs), has attracted attention in recent years with its promising applications in the chemical industries. MIL-101 is also known as "Porous Chromium Terephthalate". It has very high surface area and pore volume. MIL-101 exhibits exceptional stability against moisture and other chemicals. It also consists of coordinately unsaturated $\mathrm{Cr}$ - sites with high concentration available for catalysis and adsorption applications. MIL-101 has been synthesized by hydrothermal method and characterized by X-ray diffractometry (XRD), nitrogen adsorption and desorption analyses and SEM. XRD patterns have shown the presence of MIL-101's crystal structure with high surface area $\left(\sim 2400 \mathrm{~m}^{2} / \mathrm{g}\right)$. Nitrogen adsorption-desorption analyzes have shown that the material exhibited mesoporous material behavior.
\end{abstract}

\section{GİRIŞ (INTRODUCTION)}

Ayırma işlemlerinde kullanılacak adsorbent ya da reaksiyon çalışmalarında kullanılacak katalizörlerin performansının belirlenmesinde; gözenek yapısı, gözenek dağılımı, gözenek çapı gibi parametreler oldukça önemlidir. Metal organik yapılar yüksek yüzey alanı, yüksek metal içeriği ve moleküler boşluklar oluşturmaya elverişli kristal yapıları ile son yıllarda oldukça ilgi gören malzemelerdir [1]. Bu malzemeler, yüksek yüzey alanı ve eşsiz kristal yapı kombini ile gaz depolama, ayırma süreçleri ve kataliz uygulamaları için oldukça umut vericidir. MOFs ailesinden olan MIL-101 ilk defa 2005 yılında "Material Instıtut Lavoisier" tarafından sentezlenmiştir [2]. MIL-101 sentezi ile ilgili çalışmalar literatürde sınırlı olup mevcut yöntemin geliştirilmesine yöneliktir. Yapısında yaklaşık \%50 krom içeren MIL-101 malzemesi krom tereftalat, $\mathrm{Cr}_{3} \mathrm{~F}\left(\mathrm{H}_{2} \mathrm{O}\right)_{2} \mathrm{O}\left[\left(\mathrm{O}_{2} \mathrm{C}\right)-\mathrm{C}_{6} \mathrm{H}_{4}-\left(\mathrm{CO}_{2}\right)\right]_{3} \cdot \mathrm{nH}_{2} \mathrm{O}(\mathrm{n} \sim 25)$ olarak formüle edilmektedir. Hidrotermal sentez yöntemi ile hazırlanan MIL-101 malzemesinin BET (Brauner, Emmet and Teller) yüzey alanının $4000 \mathrm{~m}^{2} / \mathrm{g}$ 'dan daha yüksek olduğu ancak bu yüzey alanın elde etmenin de oldukça güç olduğu belirtilmiştir. Bunun sebebi sentezinde kullanılan tereftalik asitden (H2BDC, 1,4-benzenedicarboxylic acid) ileri gelen safsızlıklardır. Sentezde reaksiyona girmemiş H2BDC ya da tekrar kristalize olmuş H2BDC MIL-101 gözenek içlerinde ve dışlarında tutunmuş olması yüzey alanını düşürmektedir [3]. Sentez aşamasından çok sentez sonrası bu safsızlıkların giderilmesi önem taşımaktadır. Literatürde yapılan çalışmalarda sentez sonrasında malzeme etanol ve amonyum florür ile muamele edilmektedir [1-4]. 
MIL-101 malzemesi yüksek yüzey alanının yanısıra, Şekil 1'de ayrıntılı olarak gösterilen mikro ve mezo gözeneklerden oluşan eşsiz kristal kombini ile kimyasal proseslerde katalizör ya da adsorbent olarak kullanımı açısından umut vericidir. Şekil 1'de görüldüğü gibi temel yap1 taş1 krom oktohedralden başlayarak (a) tereftalik asit ile reaksiyona girmesiyle hibrid supertetrahedron yap1 (b) oluşur ve 1:2 oranında orta ve büyük kafesler birleşerek MIL-101 malzemesini oluşturur (c). Şekil 1 (d) ve (e)'de gösterildiği gibi MIL- 101 sadece beşgen pencerelerden (12 adet) oluşan orta kafesler (iç çapı: 2,9 nm) ve 12 adet beşgen 4 adet altıgen pencereden oluşan büyük kafeslerden (iç çapı: 3,4 nm) oluşmaktadır [2].

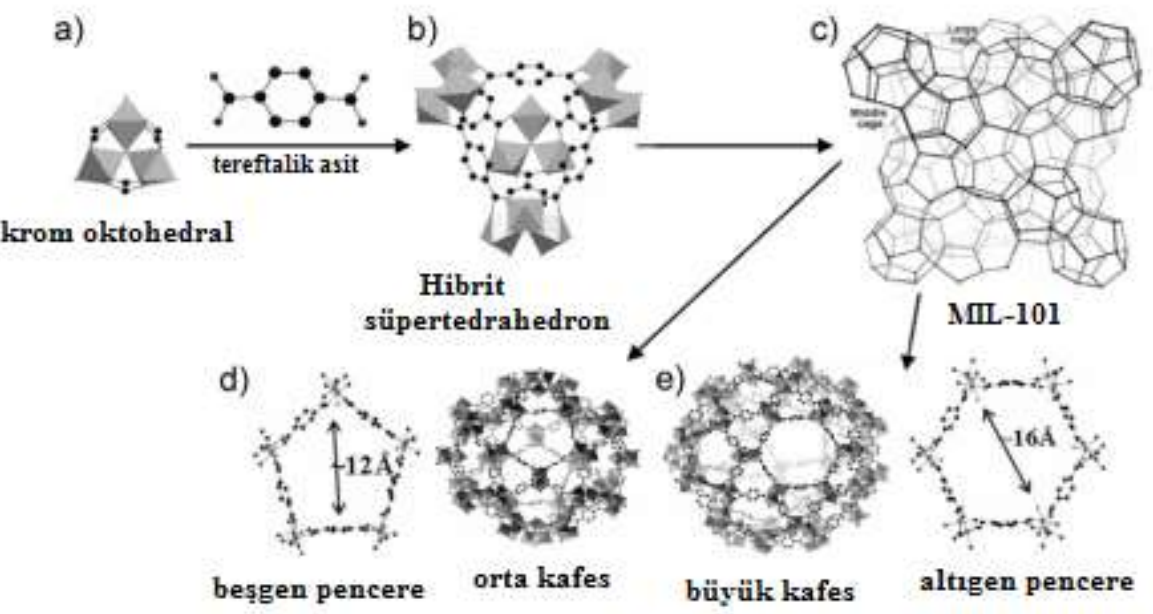

Şekil 1. MIL-101'in temel oluşum birimleri ve yapısı (Basic formation units and structure of MIL-101) [2].

MIL-101 gibi metal organik yapılar yaygın olarak sulardan ve yakıtlardan organik kirleticilerin temizlenmesine yönelik çalışmalarda adsorbent olarak kullanılmıştır [5, 6]. Ayrıca hidrofobik özelliğe sahip olmaları nedeniyle de apolar çözücülerde adsorbent olarak kullanımı avantajlıdır. Yüksek yüzey alana sahip olmaları ve gözenekliliği ile hidrojen depolama ve ilaç salınımı gibi alanlarda da kullanımı revaçtadır $[7,8]$.

Yapılan çalışma kapsamında; kimyasal proseslerde kullanılmak üzere doğrudan katalizör/adsorbent olarak ya da katalizör/adsorbent sentezinde destek malzemesi olarak görev yapması amacıyla üstün özelliklere sahip MIL-101sentezi planlanmıştır. Genel olarak MIL-101 sentezi çalışmaları iki ana bölümden oluşmaktadır. Öncelikle, tereftalik asit ile krom tuzunun hidrotermal olarak reaksiyona girmesi ile krom tereftalat oluşumu, sonrasında çeşitli çözücülerle reaksiyona girmemiş olan tereftalatın uzaklaştılarak saflaştırma işlemidir. MIL-101 sentezi üzerine yapılan çalışmalarda genel olarak sentez sonucu elde edilen kristaller süzülerek önce sicak su-etanol karışımında $80{ }^{\circ} \mathrm{C}$ 'de 24 saat, sonrasında $\mathrm{NH}_{4} \mathrm{~F}$ ile $70{ }^{\circ} \mathrm{C}$ ' de 24 saat muamele edilmiştir [1-4]. Ancak literatürde yapılan çalışmalar incelendiğinde bu yöntemin terftalik asidi uzaklaştırmadaki başarısının düşük olduğu görülmüştür. Bu amaçla yapılan araştırmalarda bulunan çözücüler tereftalik asit çözünürlüğü bakımından; metanol, $(0,1 \mathrm{~g} / 100 \mathrm{~g}$ çözücü), sülfürik asit $(2 \mathrm{~g} / 100 \mathrm{~g}$ çözücü), dimetil formamit $(6,4 \mathrm{~g} / 100 \mathrm{~g})$, dimetil sülfoksit $(19 \mathrm{~g} / 100 \mathrm{~g})$ şeklinde siralanmaktadır [9, 10]. tereftalik asitin sudaki çözünürlüğü ise oldukça $(0,0017 \mathrm{~g} / 100 \mathrm{~g})$ düşük, kloroform, eter ve asetonda çözünürlüğü yoktur $[9,10]$. MIL-101 sentezi üzerine yapılan bu çalışmada sentez sonrası kalan tereftalik asidi uzaklaştırmada farklı çözücüler denenmiş ve karakterizasyonu yapılmıştır.

\section{YÖNTEM (METHOD)}

MIL-101 sentezi 4 mmol tereftalik asit ve $4 \mathrm{mmol}\left(\mathrm{CrNO}_{3}\right)_{3} \cdot 9 \mathrm{H}_{2} \mathrm{O}$ ve $20 \mathrm{ml}$ deiyonize su oda sıcaklı̆̆ında yaklaşık 1 saat manyetik karıştırıcı ile karıştırılmış, ardından otoklav reaktörde $210{ }^{\circ} \mathrm{C}$ 'de 10 saat 
hidrotermal sentezi gerçekleştirilmiştir [1,2]. Reaksiyona girmemiş fazla tereftalik asidi uzaklaştırma amacıyla yapılan yıkama işleminde farklı çözücülerin (dimetil formamit (DMF), dimetil sülfoksit (DMSO) ve metanol ile DMF'in ardı ardına kullanıldığı çözücü sistemi) etkisi araştırılmıştır. DMF ile yıkama işleminde; otoklav reaktörden çıkan numune filtrelenip $60 \mathrm{ml}$ DMF ile otoklav reaktör içerisinde karıştırılıp $150{ }^{\circ} \mathrm{C}$ 'de 24 saat etüvde muamele edilmiştir. Muamele sonrası filtre edilen malzeme, kalan DMF'nin uzaklaştırılması amacıyla $150{ }^{\circ} \mathrm{C}$ 'de 24 saat etüvde kurutulmuştur. DMSO ile yıkama işeminde; sentez sonrası numune filtrelenip $60 \mathrm{ml}$ DMSO ile oda sıcaklığında 24 saat muamele edilmiştir. İşlem sonrası filtre edilen malzeme, kalan DMSO'nun uzaklaştırılması amacıyla $150^{\circ} \mathrm{C}$ 'de 24 saat etüvde kurutulmuştur. Metanol ve DMF ile yıkama işleminde ise sentez sonrası reaktörden çıkan numune filtrelenip $60 \mathrm{ml}$ metanol ile yıkanıp sonrasında tekrar filtre edilip $60 \mathrm{ml}$ DMF ile otoklav reaktör içerisinde karıştırılıp $150{ }^{\circ} \mathrm{C}$ ' de 24 saat etüvde muamele edilmiştir. İşlem sonrası malzeme, kalan DMF'nin uzaklaştırılması amacıyla 150 ${ }^{\circ} \mathrm{C}^{\prime}$ de 24 saat etüvde kurutulmuştur.

Malzemelerin öncelikli karakterizasyonu X-1şını kırınım desenleri (XRD) ile yapılmış olup, MIL-101 kristal yapısı başarıyla elde edilen malzemenin yüzey alanını ve gözenekliliğini belirleme amacıyla azot adsorpsiyon-desorpsiyon analizleri yapılmış ve yüzey karakterizasyonu da taramalı elektron mikroskobu (SEM) ile gerçekleştirilmiştir.

\section{BULGULAR VE TARTIŞMA (FINDINGS AND DISCUSSION)}

Yapılan çalışmada kimyasal proseslerde adsorbent ve katalizör olarak doğrudan ya da destek malzemesi olarak kullanılabilecek MIL-101 malzemesi sentezlenmiştir. MIL-101 yüzey alanı $4000 \mathrm{~m}^{2} / \mathrm{g}$ 'dan daha yüksek olabilmekteyken, sentez kimyasallarından ileri gelen safsızlıklardan ötürü bu kadar yüksek yüzey alanları elde etmek oldukça zordur. Yapılan çalışmada farklı yıkama prosedürleri kullanılarak sentez sonrasında reaksiyona girmeden kalan tereftalik asidin fazlasının uzaklaştırılması amaçlanmıştır. Yıkama prosedürü sonrası elde edilen malzemelerin MIL-101 karakteristik yapısının tayini için XRD analizi yapılmıştır. MIL-101 yapısal tayinini için X-ışınımı kırınım desenleri 20; 2-20 aralığında incelenmiştir. Farklı çözücüler kullanılarak sentezleri tamamlanan MIL-101 malzemelerine ait XRD desenleri Şekil 2'de verilmiştir. MIL-101 karakteristik olarak 2Ө; 0-12 arasında pikler vermektedir [1,2]. Sentezi yapılan MIL101'e ait XRD desenleri incelendiğinde MIL-101 kristal yapısını desteklediği görülmüştür. MIL-101'in karakteristik yapısı dışındaki 2Ө;15-20 arasındaki piklerin tereftalik aside ait olduğu düşünülmektedir.

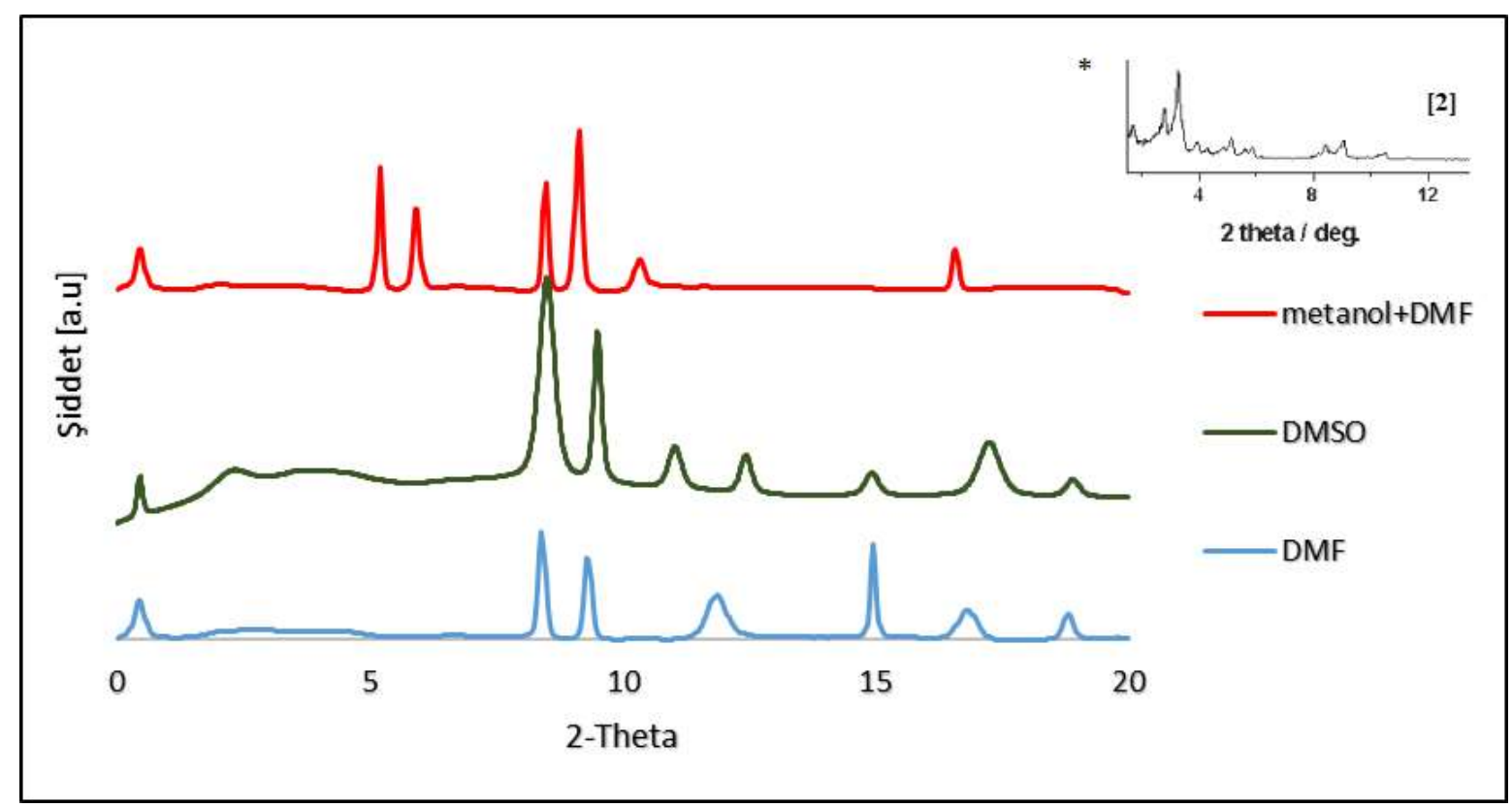

Şekil 2. Sentezlenen MIL-101 malzemelerine ait XRD desenleri -* literatürden alınan xrd örneği (XRD patterns of synthesized MIL-101 materials -* xrd example from literature) 
Tereftalik asidi uzaklaştırmak üzere sentez sonrası DMF ile $150{ }^{\circ} \mathrm{C}$ 'de 24 saat yapılan muamele işlemi yapılan malzemeye ait XRD desenleri incelendiğinde 2Ө;15-20 arasındaki piklerin varlığı ortamda hala tereftalik asit bulunduğunu göstermektedir. Ortamda kalan tereftalik asit gözenekler arasında bloklaşarak önemli yansımaların oluşmasını engellemektedir. Özellikle MIL-101'e ait 2Ө;4-5 arasındaki karakteristik yansımalar görülmemiştir.

DMSO ile yapılan yıkama işlemi sonrasında da DMSO'nun oda sıcaklığında yeteri kadar başarılı olmadığ 1 görülmektedir. Ancak bu malzemenin korozif olması ve kokusu gibi bazı fiziksel olumsuzlukları nedeniyle daha yüksek sıcaklıklarda laboratuar şartlarında kullanımı mümkün olamamaktadır. Yine de DMF ile kıyaslandığında benzer yansımalar verdiği görülmüştür.

Metanolle ön yıkama yapılıp DMF ile muamele edilen malzemenin ise tereftalik asitden ileri gelen safsızlıklarının giderildiği görülmüştür. Bu malzemenin kristal yapısı karakteristik MIL-101 kristal yapısına ait pikleri içermektedir. Özellikle $2 \Theta ; 4-5^{\circ}$ arasında MIL-101'e ait karakteristik yansımalar görülmektedir.

Bilindiği üzere sentezde kullanılan tereftalik asidin fazlası MIL-101 gözeneklerini tıkayarak yüksek yüzey alanlı malzeme elde edilmesini engellemektedir. Tereftalik asidi uzaklaştırmak üzere sentez sonrası sadece DMF ile yıkama yeterli gelmemekte metanol ile ön yıkama işlemi daha başarılı sonuç vermektedir. Yapılan azot adsorpsiyon- desorpsiyon analizleri de bu sonucu doğrulamaktadır. Şekil 3'de bu malzemeye ait azot adsorpsiyon- desorpsiyon izotermi verilmiştir. Hazırlanan adsorbentler BDDT (Brunauer-DemingDeming-Teller) sınıflandırması içerisinde IV. tip izoterme benzemektedir. Bilindiği üzere mezogözenekli malzemeler IV. tip adsorpsiyon davranışı göstermektedirler. Buna dayanarak da sentezlenen MIL-101 malzemesinin mezogözenek yapısına sahip olduğunu ve ideal adsorpsiyon davranışı gösterdiğini söylemek mümkündür. Bununla birlikte malzemenin BET yüzey alanı $2400 \mathrm{~m}^{2} / \mathrm{g}$ olarak tayin edilmiștir. Elde edilen yüksek yüzey alanı çeşitli reaksiyonlarda kullanılmak üzere aktif bir bileşen emdirilerek uygun katalizör sentezine olanak kılmaktadır. Ayrıca adsorpsiyon uygulamalarında doğrudan kullanımında da umut vericidir.

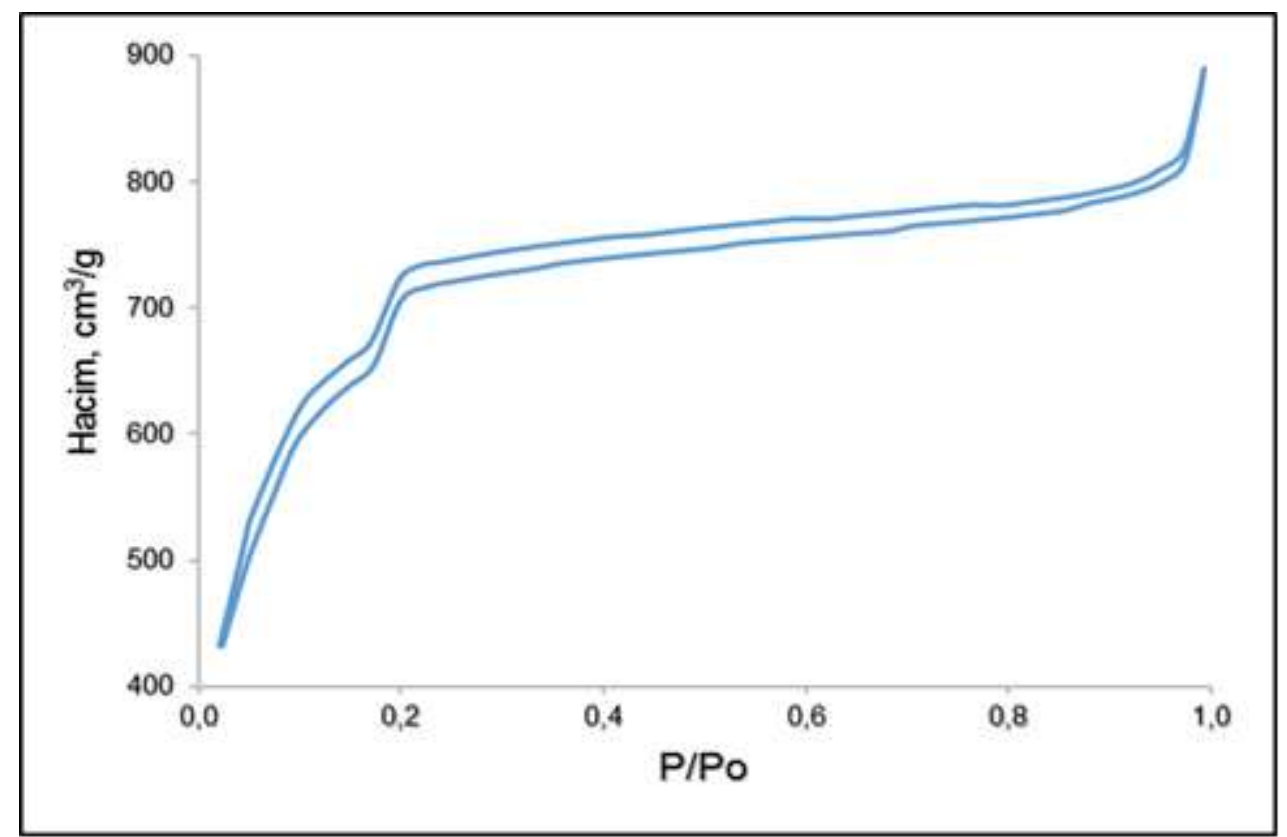

Şekil 3. MIL-101' ait azot adsorpsiyon-desoprsiyon izotermi (Nitrogen adsorption-desorption isoterms of MIL-101)

Malzemenin gözenek boyut dağılımını incelemek üzere Barrett, Joyner ve Halenda (BJH) metodu kullanılmıştır. Şekil 4'de verilen BJH izotermi azot adsorpsiyon davranışlarına göre çizilmiştir. Malzeme iki dağılımlı davranış göstermektedir. Mezogözenek çapı ortalama $2 \mathrm{~nm}$ olarak belirlenirken mikro gözenek 
çapı ortama 1,5 nm'dir. İzoterm davranışı izlendiğinde homojen bir dağılım vermesi oldukça önemlidir. Malzeme mikro ve mezo gözenek bölgelerinde homojen bir dağılım göstermiştir.

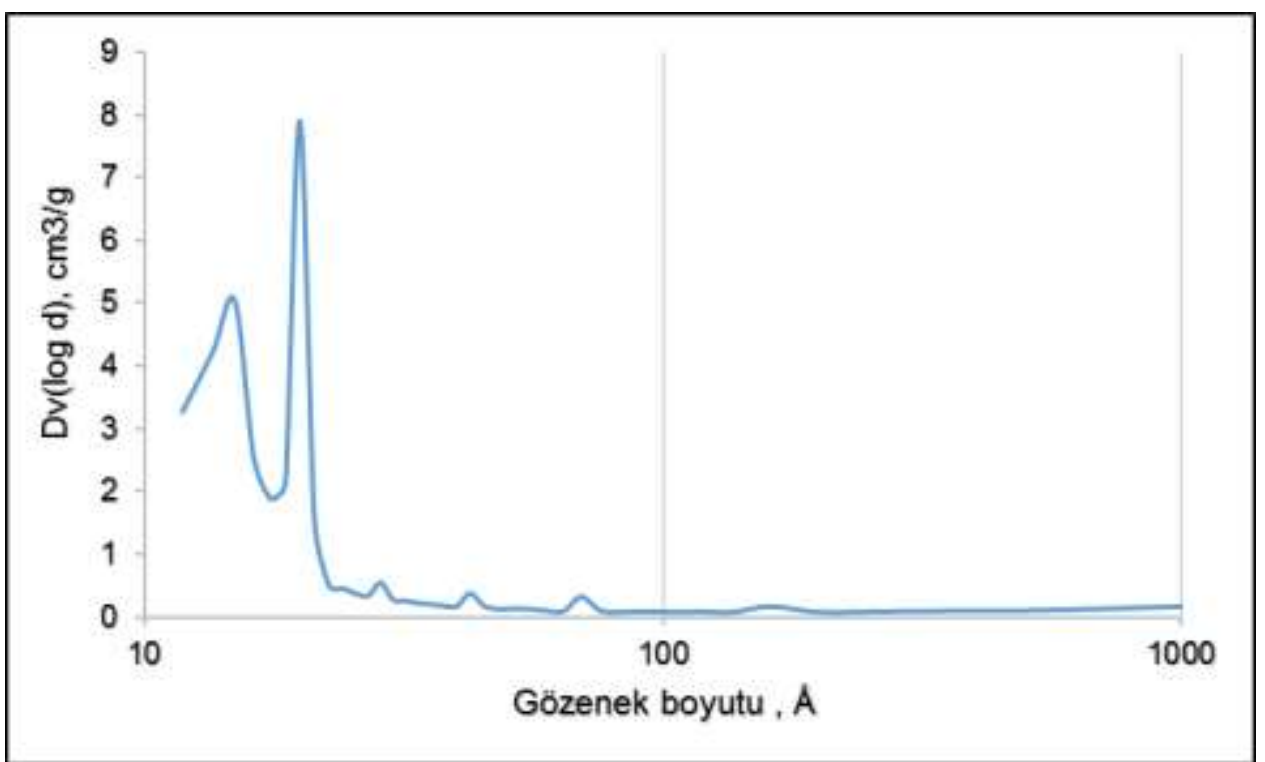

Şekil 4. MIL-101'e ait gözenek boyut dağılımı (Pore size distribution of MIL-101)

Yapılan karakterizasyon tetkikleri neticesinde sentez sonrası fazla terftalik asidin uzaklaştrırılması amacıyla metanol ve DMF ile yıkama işleminin oldukça başarılı olduğu görülmektedir. Şekil 5'de bu malzemeye ait SEM görüntüsü verilmiştir. SEM fotoğrafından görüldüğüü üzere MIL-101 oktahedral yapısı başarı ile elde edilmiştir. Fotoğrafta görülen iki ince çubuk sentez sonrası uzaklaştırılamayan tereftalik asit kristalleridir. Yüzey alanının oldukça yüksek elde edilmesi saflaştırma işleminin başarılı olduğunu göstermektedir.

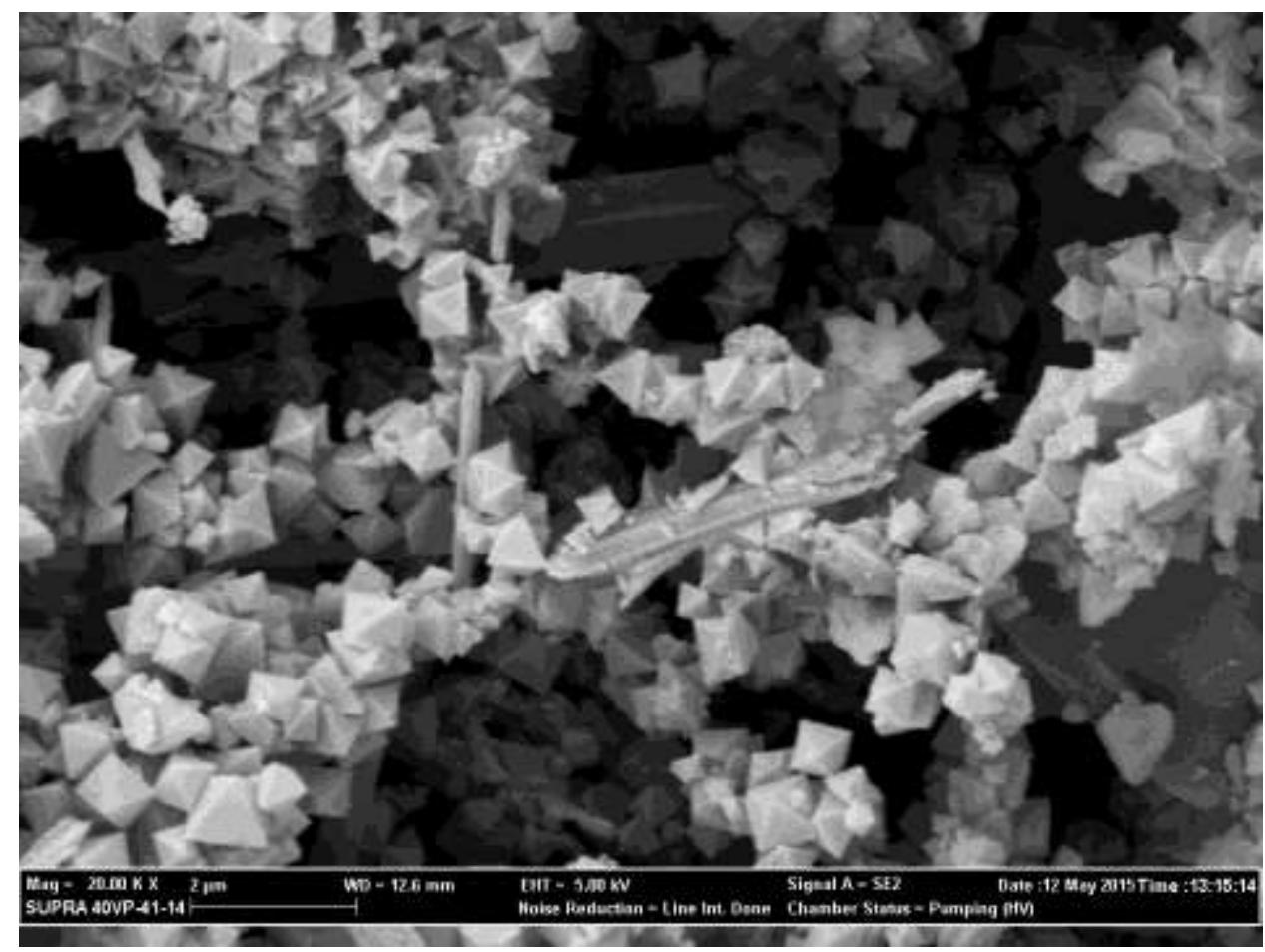

Şekil 5. MIL-101'e ait SEM görüntüsü (SEM image of MIL-101) 
MIL-101 son yıllarda gündeme gelmiş ve geniş kullanıma açık potansiyel bir adsorbent/katalizör malzemesidir. Yapılan çalışma kapsamında elde edilen ve karakterizasyonu yapılan üstün özellikli MIL101 malzemesi çeşitli reaksiyonlarda ya da adsorpsiyon işlemlerinde, katalizör ya da adsorbent olarak kullanımı açısından umut vericidir.

\section{SONUÇLAR (CONCLUSIONS)}

Yapılan çalışma ile krom-tereftalat bazlı bir malzeme olan MIL-101 için sentez aşaması sonrası saflaştırma işlemlerinde kullanacak çözücüler araştırılmıştır. Tereftalik asit açısından enyüksek çözünürlüğe sahip dimetil formamit ve dimetil sülfoksit denenmiştir. Dimetil formamidin tereftalik asit uzaklaştırmada hem daha iyi olduğu hem de işlem uygulanabilirliği açısından elverişli olduğu görülmüştür. XRD desenleri incelendiğinde metanolle ön y1kama yapılıp DMF ile muamele edilen malzemenin karakteristik MIL-101 yansımalarını verdiği görülmüştür. Azot adsorpsiyon-desorpsiyon analizi yapılan malzemenin (metanol ve DMF ile yıkanan) mezogözenek davranışı sergilediği aynı zamanda gözenek boyut dağılımda mikro ve mezogözenek bölgesinde homojen bir dağılım verdiği görülmüştür. $\mathrm{Bu}$ malzemenin SEM yüzey fotoğrafları çekilerek MIL-101'e ait oktohedral yapıdaki partiküller gözlenmiştir. MIL-101 son yıllarda gündeme gelmiş ve geniş kullanıma açık potansiyel bir adsorbent/katalizör malzemesidir. Yapılan çalışma ile MIL-101 sentezine dair ayrıntılı bilgi verilmiş ve yıkama prosedürü için alternatif çözücüler denenmiştir. Sentez ve karakterizasyon çalışması sunulan malzeme yüksek yüzey alanı ve eşsiz kristal yapı kombini ile gaz depolama, ayırma süreçleri ve kataliz uygulamaları için oldukça umut vericidir.

\section{TEŞEKKÜR (ACKNOWLEDGMENTS)}

Bu çalışma, 06/2015-09 nolu Gazi Üniversitesi Bilimsel Araştırma Projeleri tarafından desteklenmiştir.

\section{KAYNAKLAR (REFERENCES)}

[1] Henchel, A., Gedrich, K:, Kraehnert, R., Kaskel, S., “ Catalaytic properties of MIL-101”, Chemical Communications, Cilt 35, 4192-4194, 2008.

[2] Hong, D-Y., Hwang Y.K., Serre, C., Fe'Rey, G., Chang J-S., "Porous Chromium Terephthalate MIL101 with Coordinatively Unsaturated Sites: Surface Functionalization, Encapsulation, Sorption and Catalysis", Advanced Functional Materials, Cilt 19, 1537-1552, 2009.

[3] Lee, Y-R., Kım, J., Ahn W-S., "Synthesis of metal-organic frameworks, Department of Chemistry and Chemical Engineering”, Korean Journal of Chemical Engineering, Cilt 309: 1667-1630, 2013.

[4] Park, E.Y., Hasan, Z, Ahmed, I., Jhung, S.H., "Preparation of aComposite of Sulfated Zirconia/Metal Organic Framework and its Application in Esterification Reaction", Bull.Korean Chemical Soceity, Cilt 35, 1659-1664, 2014.

[5] Behvandi, A, Safekordi, A.A., Khorasheh, F, "Removal of benzoic acid from industrial wastewater using metal organic frameworks: equilibrium, kinetic and thermodynamic study" Journal of Porous Materials, Cilt 24, No 1, 165-178, 2017.

[6] Darunte, L.A., Oetomo, A.D., Walton, K.S., Sholl, D.S., Jones, C.W., "Direct Air Capture of CO2 Using Amine Functionalized MIL-101(Cr)" ACS Sustainable Chemistry \& Engineering, Cilt 4, No 10, 5761-5768, 2016.

[7] Blanita, G., Streza, M., Lazar, M.D., Lupu, D., "Kinetics of hydrogen adsorption in MIL-101 single pellets", International Journal Of Hydrogen Energy, Cilt 42, No 5, 3064-3077, 2017. 
[8] Preiss, T., Zimpel, A., Wuttke, S., Radler, J.O., "Kinetic Analysis of the Uptake and Release of Fluorescein by Metal-Organic Framework Nanoparticles", Materials, Cilt 10, No 2, 216, 2017.

[9] Lewis, R. J. Sr. "Hawley's Condensed Chemical Dictionary (15. Basım)", John Wiley \& Sons., New York, 2007.

[10] Park, C. M., Sheehan R.J., "Phthalic Acids and Other Benzenepolycarboxylic Acids", Kirk-Othmer Encyclopedia of Chemical Technology, John Wiley \& Sons. New York, 2000. 